\title{
Coulisses
}

Revue de théâtre

2 | Automne 1990

Spécial Festival des idées : Besançon ville ouverte aux jeunes

\section{Terres de brume, ou la Chanson des Nibelungen}

\section{Rédaction}

\section{(2) OpenEdition}

Journals

Édition électronique

URL : http://journals.openedition.org/coulisses/1607

DOI : 10.4000/coulisses. 1607

ISSN : 2546-9460

Éditeur

Presses universitaires de Franche-Comté

\section{Édition imprimée}

Date de publication : 1 novembre 1990

Pagination : $\mathrm{np}$

ISSN : 1150-594X

\section{Référence électronique}

Rédaction, «Terres de brume, ou la Chanson des Nibelungen », Coulisses [En ligne], 2 | Automne 1990, mis en ligne le 04 juillet 2017, consulté le 23 octobre 2019. URL : http://journals.openedition.org/ coulisses/1607 ; DOI : 10.4000/coulisses.1607

Ce document a été généré automatiquement le 23 octobre 2019.

Coulisses 


\title{
Terres de brume, ou la Chanson des Nibelungen
}

\author{
Rédaction
}

1 Terres de brume est un spectacle présenté par l'atelier du Centre de Rencontres, mis en scène par Patrick Melior, Cet atelier, qui se déroule sur une année, accueille des amateurs, la règle du jeu étant de monter un spectacle sans exigence d'exploitation.

\section{La Chanson des Nibelungen}

2 Le texte source est un long poème écrit au début du xiII ${ }^{\mathrm{e}}$ siècle par un auteur germanique dont on ignore l'identité et qu'on suppose être un jongleur récitant ses œuvres de châteaux en cours princières. Le Nibelungslied ou Chanson des Nibelungen est l'épopée la plus populaire de la littérature allemande médiévale dont les héros légendaires sont Sigfrid, Kriemhild, Brünhild, Hagen...

En pays burgonde grandissait une fille de très noble lignage. En aucun pays, il n'en était de plus belle. Elle avait nom Kriemhild; elle devint une dame d'une grande beauté. A cause d'elle beaucoup de héros durent perdre la vie.

La Chanson des Nibelungen c'est principalement l'histoire de Kriemhild. L'auteur nous raconte comment Kriemhild, princesse burgonde devient l'heureuse épouse de Sigfrid, fils du roi de Néerlande et comment celui-ci est traîtreusement assassiné par Hagen, baron de la cour burgonde. Ce meurtre déclenchera la terrible vengeance de Kriemhild; le poème se termine en tragédie sanglante par le massacre des princes burgondes et la mort de l'héroïne. L'histoire est ici résumée à grands traits. Le poème forme un ensemble beaucoup plus touffu, fait de l'agencement de multiples épisodes : la conquête de Brünhild, reine d'Islande, par Gunther, roi des Burgondes (et frère de Kriemhild) ; la querelle des deux reines; le remariage de Kriemhild avec Etzel, roi des Huns; la mort du fils de l'héroïne, tué par Hagen; l'incendie du bâtiment où sont enfermés les Burgondes... 
Je ne puis vous retracer ce qui arriva depuis lors: je sais seulement que l'on vit chevaliers et dames, et en outre de nobles écuyers, pleurer la mort de leurs amis chers. Ici finit le conte : c'est la Détresse des Nibelungen.

4 C'est cette même légende, profondément transformée qui a inspiré la monumentale fresque sonore de Wagner, L'anneau du Nibelung. L'adaptation que propose Patrick Melior se démarque de l'interprétation wagnérienne par un retour aux sources de la légende.

\section{Le spectacle}

5 La représentation a lieu sous un chapiteau installé promenade Granvelle. La terre nue convient à la matière brute de héros menés par de fortes passions. Un côté ouvert sur les rocailles du parc fournit un mini décor wagnérien : sur un fond de nuit bleuté se détachent les formes baroques des rochers, le sombre feuillage des arbres et le miroitement de l'eau. Les corbeaux, partenaires inattendus, apportent gracieusement au spectacle leur partition sonore. Les personnages entrent un par un et construisent un cercle de pierres, autre matière brute, espace scénique dans lequel se dérouleront la plupart des épisodes. Le rituel accompli, l'histoire commence.

6 La couleur dominante de Terres de brume n'est pas le tragique. Certes, les événements relatés ou montrés sont repris du conte germanique et ici aussi tout se termine dans un bain de sang.

7 Kriemhild reste le personnage dramatique du poème. Mais l'un des partis pris de mise en scène est le burlesque ; ainsi le spectacle est traversé par une intention parodique, parsemé de clins d'œil à la convention germanique et joue sur le décalage. Gunfher, le roi burgonde, blouson de cuir noir porté à nu et boucle d'oreille, tient du loubard de bitume. Le personnage du récitant est à un moment incarné par un randonneur, chapeau tyrolien à plumet et courte culotte bavaroise à bretelles, qui narre un épisode de l'existence agitée des Burgondes en croquant une tablette de chocolat Suchard. Surprise de la distribution, la reine Brünhild est jouée par un jeune homme vigoureux à l'œil bleu et à la chevelure blonde. Il est vrai que dans le texte original, Brünhild est une sorte de force de la nature :

Il était une reine qui résidait au-delà de la mer. On n'en connaissait aucune autre qui pût lui être comparée. Elle était d'une beauté sans pareille, sa force était très grande. Elle se mesurait au jet du javelot, avec les vaillants chevaliers qui briguaient son amour. légitimité Brünhild la nuit venue et comment celle-ci entre dans une violente colère, lie le roi pieds et poings et le suspend à un crochet du mur.

Il s'en fallut de peu

- tant elle était vigoureuse -

qu'elle

ne le fît périr.

10 Cet événement transcrit dans la Chanson des Nibelungen sur le mode sérieux, est dans le spectacle traité dans une perspective comique. Les démêlés conjugaux de Gunther et Brünhild se déroulent derrière un paravent dont les agitations donnent au spectateur la mesure du différend. 
11 À la fin, chaque personnage reprend sa pierre et déconstruit le cercle. Le spectacle est terminé.

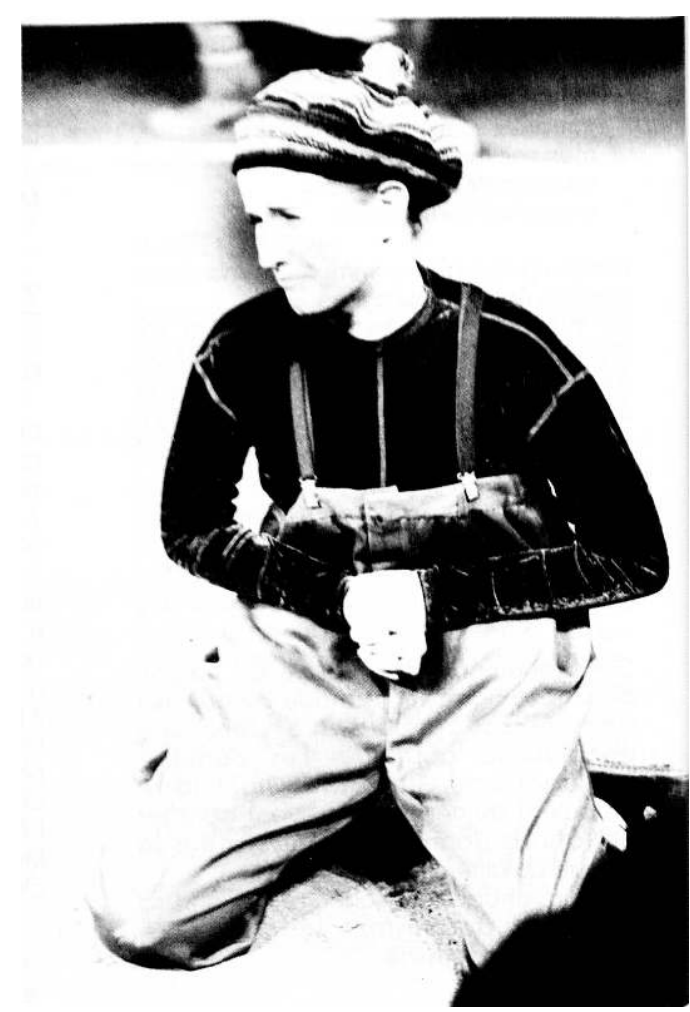

(c) Collectif Photo BVOJ 90.

\section{Entretien avec Patrick Melior}

Terres de Brume est une adaptation que Patrick Melior a écrite, il y a plus de cinq ans et qu'il a ressortie de ses cartons pour travailler avec le groupe de l'atelier qu'il anime.

En début d'année, il y avait un groupe important; il fallait trouver un sujet qui puisse faire travailler tout le monde. J'ai proposé les Nibelungen que j'avais failli monter deux fois déjà ; il y avait en moi un fond de déception de n'avoir pas pu le faire...

\section{Sur le lieu scénique}

Au départ, je voulais une forme de théâtre se rapprochant du cirque, avec la scène en rond. On marque son terrain et on joue dedans avec très peu de moyens... Un spectacle amateur est fait de beaucoup de hasard. Au fond, j'étais très heureux de ne pas avoir de moyens. Le chapiteau, les rochers, c'est le hasard qui nous a mis en présence du plus conventionnel des décors, un décor presque wagnérien; ce que je ne ferais pas si j'avais à mettre en scène un opéra de Wagner.

\section{Mythes, légendes et actualité}

13 Patrick Melior a déjà travaillé sur les grands mythes; il a notamment écrit et mis en scène un Faust, la Chanson des Nibelungen rejoint une autre ligne directrice de son travail : la tragédie antique. 
La vengeance de Kriemhild me fait penser aux Atrides, à Médée capable de sacrifier ses enfants pour assouvir sa vengeance. Jusqu'où la passion peut-elle aller? Aux pires horreurs. C'est le même thème que l'on retrouve dans les Nibelungen.

J'ai retrouvé il y a un an l'adaptation que j'avais faite et j'ai découvert ce que je n'avais pas vu la première fois. En fait, c'est l'actualité qui m’a éclairé sur mon propos... les résurgences de l'idéologie nazie... Toutes ces légendes ont été récupérées par le pouvoir nazi. L'œuvre est une matière brute; en passant à la scène, en me laissant porter par ce qui est dit, j'ai été amené à découvrir que j'étais proche des chansons de geste du Moyen Âge mais sans l'amour courtois. Ici, c'est plus brutal, plus primaire, plus violent...

\section{Illusion et vérité}

Si je suis metteur en scène, c'est parce que je rêvais de mettre en scène de l'opéra. J'ai beaucoup rêvé d'opéra derrière mon tourne-disque. J'ai mis en scène La Voix humaine de Poulenc. C'est un travail qui nécessite beaucoup de précision, une collaboration étroite avec le chef d'orchestre, les musiciens. La musique a sa vérité propre qu'on ne peut pas contourner. Une phrase musicale a un tempo, il y a une présence avec laquelle on ne peut pas tricher. Une phrase de texte, on peut lui faire dire tout ce qu'on veut. Je pense que ce qui est important, c'est de révéler une vérité ; ça peut passer par la paillette, le mensonge, l'illusion... C'est là, le paradoxe sur le métier du théâtre : on est dans un domaine où on est toujours confronté à la notion de vérité parce qu'on est sans cesse dans le monde de l'illusion et du mensonge. 